\title{
Decline in Search Speed and Verbal Memory Over 26 Years of Midlife in a British Birth Cohort
}

\author{
Daniel Davis $^{\mathrm{a}}$ Rebecca Bendayan ${ }^{\mathrm{a}} \quad$ Graciela Muniz Terrera $^{\mathrm{b}}$ Rebecca Hardy ${ }^{\mathrm{a}}$ \\ Marcus Richards ${ }^{\mathrm{a}}$ Diana Kuh $^{\mathrm{a}}$ \\ ${ }^{a}$ MRC Unit of Lifelong Health and Ageing at UCL, London, UK; ${ }^{b}$ Centre for Dementia Prevention, University of \\ Edinburgh, Edinburgh, UK
}

\section{Keywords}

Ageing $\cdot$ Cognition $\cdot$ Trajectory $\cdot$ Life course epidemiology

\section{Keywords}

Background: Cognitive capabilities change in later life, although their onset and rate of decline, and how they are shaped by lifetime socioeconomic position, childhood cognition and adult health status are all unclear. Methods: From the Medical Research Council National Survey of Health and Development, we analysed 3,192 participants undergoing one or more cognitive assessments at ages $43,53,60-64$ and 69. Linear mixed models described cognitive trajectories, adjusting for factors across the life course. Results: For both search speed and verbal memory, better performance at age 43 (the intercept) was associated with higher paternal and own education, childhood cognition, and adult occupational class. For search speed, the trajectory was best described as a quadratic function (decline of 45.6 letters/5-years +4.6 letters). Verbal memory showed a linear decline of 0.20 words/5-years between ages 43 and 60 and a steeper linear decline of 0.95 words/5-years between ages 60 and 69. Decline in verbal memory in the latter period was steeper in those with higher educational achievements at age 26 (ad- ditional 0.28 words $/ 5$-years for highest attainment). Conclusions: Decline in verbal memory and search speed across midlife is evident, though with different non-linear trajectories. By implication, pathways to cognitive impairment and dementia in older age may have their origins in this period.

C 2017 The Author(s)

Published by S. Karger AG, Basel

\section{Introduction}

Cognitive capability, the capacity to undertake the mental tasks of daily living, forms an integral part of healthy ageing, and factors across life are likely to underpin this [1]. In a population with rising longevity, there is clear heterogeneity in cognitive function, widening with progressing age and illness [2]. Optimal cognitive capability in late life depends largely on the experience of individuals in middle age [3]. Yet, little is known about when different cognitive functions begin to decline and the extent that these are shaped by social and biological factors earlier in the life course.

Most studies examining the variation in cognitive function by age are cross-sectional, which may overesti-

\begin{tabular}{ll}
\hline KARGER & $\begin{array}{l}\text { ( 2017 The Author(s) Karger } \\
\text { Published by S. Karger AG, Basel Open caccess }\end{array}$ \\
E-Mail karger@karger.com & $\begin{array}{l}\text { This article is licensed under the Creative Commons Attribution 4.0 } \\
\text { International License (CC BY) (http://www.karger.com/Services/ } \\
\text { OpenAccessLicense). Usage, derivative works and distribution are } \\
\text { permitted provided that proper credit is given to the author and the } \\
\text { original publisher. }\end{array}$
\end{tabular}


mate differences due to secular changes in educational attainment [4]. This is evident in findings from the Seattle Longitudinal Studies, which follow cohorts in 7-year age bands, recruited every 7 years, assessed at 7-year intervals [5]. Here, cross-sectional (inter-individual) and longitudinal (intra-individual) differences can be compared, with little longitudinal change observed before age 60, consistent across several cognitive domains. In the Whitehall II study, although cross-sectional differences at baseline were larger than subsequent longitudinal change, decline was still apparent in reasoning, verbal fluency and verbal memory over 10 years from age 45 [6]. The Medical Research Council (MRC) National Survey of Health and Development (NSHD) reported a small decline in verbal memory and search speed in adults tested at ages 43 and 53, with greater declines observed in those with lower cognitive ability in childhood [7]. Both public health and individual interventions in those with low levels of performance, or a steeper than average decline, may therefore improve cognitive capability when they grow older $[8,9]$.

In this analysis, we used data from NSHD, the oldest of the British birth cohort studies, to describe trajectories of change in visual search speed and verbal memory over a 26-year-period from age 43 to 69 . These tests were chosen to represent two fundamental aspects of fluid ability, speed of processing and episodic memory, which are sensitive to age and morbidity-associated decline and also relatively easy to measure repeatedly over time [10]. As NSHD provides a rare opportunity to include earlier life factors, we also investigated whether family background, childhood cognition and educational attainment were associated with these cognitive domains at 43 and their change with age, also accounting for adult socio-economic position (SEP), health status and unavoidable attrition due to mortality.

\section{Methods}

The NSHD is a birth cohort following up 5,362 individuals born during one week in March 1946 in England, Scotland and Wales [11, 12]. Representativeness has been maintained over time [13-15]. This report uses data collected over 24 assessments from birth. In 1989 (at age 43), of the 3,749 participants remaining in the study, 3,262 (87\%) were assessed [11]; the majority of these participants (3247) had been flagged for death notification on the National Health Service Central Register. Of these, 3,192 (98\%) had at least one cognitive assessment of verbal memory or search speed at this follow-up or at subsequent follow-ups at ages 53, 6064, and 69; this is the overall sample for analysis [16]. Ethical approval was obtained from the Multicentre Research Ethics Com- mittee (for data collections up to 2010) and Queen Square Research Ethics Committee (14/LO/1073) and the Scotland Research Ethics Committee (14/SS/1009) for data collections between 2014 and 2015 .

\section{Visual Search Speed and Verbal Memory}

All assessments at each of the 4 follow-ups (ages 43, 53, 60-64, and 69) were carried out at home or clinic visits by research nurses according to a standardised protocol. The visual search speed task required participants to cross out the letters $\mathrm{P}$ and $\mathrm{W}$, randomly embedded within a grid of other letters in one minute. The score represents the total number of letters searched (maximum 600 , except for at age 43 where maximum score was 450 ). Verbal memory was assessed through the recall of a 15-item word learning task, where each word was presented for 2 seconds. The score represents the total number of words correctly recalled over 3 identical trials (maximum 45). To minimise practice effects, 2 different word lists were alternated between follow-ups.

\section{Mortality}

We included deaths from any cause from March 1989 (43 years) until February 2016 (the end of the 69th year) notified through NHS Digital (previously the Office for National Statistics).

\section{Covariates}

Variables were chosen on the basis of factors previously demonstrated to be associated with adult cognition in NSHD [16, 17]. In childhood, paternal education (primary or none, more than primary) was used as a measure of childhood SEP. Childhood cognition was measured at age 8 , using a battery of tests administered by participants' school teachers: reading comprehension, pronunciation, vocabulary, and non-verbal reasoning [18]. Childhood cognitive test scores were summed and standardised to the final sample. Where data on childhood cognition were missing at age 8 $(n=366)$, Z-scores from the assessment at age 11 or 15 were used ( $n=89$ and $n=42$, respectively). Educational attainment by age 26 was classified in 3 categories: below ordinary secondary qualifications (vocational); ordinary secondary qualifications ("O" levels and their training equivalents), advanced secondary qualifications ("A" levels and their equivalents) and above.

At age 43, adult SEP was based on participants' occupational class (I and II; IIINM and IIIM; IV and V). Measures of health status at this age included systolic blood pressure (of 2 measurements using a sphygmomanometer, the second measure was used if available), body mass index (BMI) calculated by measured height and weight; self-reported diabetes, stroke and cancer, and the World Health Organization Rose angina scale [19]. Smoking status (current, former, never) was also recorded.

\section{Statistical Analyses}

Linear mixed models were used to examine the trajectories of verbal memory and search speed, the intercept being set at age 43 . Where data were skewed, models were adjusted using the Kenward-Roger procedure [20,21]. Chronological age since 43, scaled in a 5-year unit to facilitate the interpretation of possible quadratic terms, was used as the time metric. Linear and nonlinear models with random intercepts and slopes were examined and the fit of the models was compared using the Bayesian Information Criterion (BIC). Linear and quadratic models were tested under the assumption that decline begins at age 43 and this de- 
Table 1. Characteristics of 3,185 NSHD participants cognitively assessed in adult and childhood

\begin{tabular}{|c|c|c|c|c|}
\hline & $n$ or mean & $\%$ or SD & Missing & $\%$ \\
\hline Men, $n(\%)$ & 1,611 & 51 & 0 & 0 \\
\hline \multicolumn{5}{|l|}{ Earlier life factors } \\
\hline Father's education by age $6,>$ primary, $n(\%)$ & 1,271 & 40 & 218 & 7 \\
\hline General cognition in childhood, mean (SD) & 0 & 1 & 0 & 0 \\
\hline Educational attainment by age $26, n(\%)$ & & & 104 & 3 \\
\hline$<$ Ordinary level, $n(\%)$ & 1,167 & 67 & & \\
\hline Ordinary level, $n(\%)$ & 855 & 27 & & \\
\hline Advanced level, $n(\%)$ & 1,059 & 33 & & \\
\hline \multicolumn{5}{|l|}{ Adult factors at age 43} \\
\hline $\mathrm{BMI}, \mathrm{kg} / \mathrm{m}^{2}$, mean $(\mathrm{SD})$ & 25.5 & 4.2 & 221 & 7 \\
\hline Systolic BP, mm Hg, mean (SD) & 123 & 16 & 252 & 8 \\
\hline Diabetes, $n(\%)$ & 29 & 1 & 199 & 7 \\
\hline Smoking status, $n(\%)$ & & & 199 & 7 \\
\hline Current & 897 & 28 & & \\
\hline $\mathrm{Ex}$ & 1,240 & 39 & & \\
\hline Never & 849 & 27 & & \\
\hline Positive WHO Rose angina score, $n(\%)$ & 102 & 3 & 197 & 6 \\
\hline Stroke, $n(\%)$ & 10 & 0 & 194 & 6 \\
\hline Cancer, $n(\%)$ & 54 & 2 & 207 & 7 \\
\hline Occupational class, $n(\%)$ & & & 47 & 1 \\
\hline I + II & 1,335 & 42 & & \\
\hline III NM + M & 1,299 & 41 & & \\
\hline $\mathrm{IV}+\mathrm{V}$ & 504 & 16 & & \\
\hline
\end{tabular}

cline might be constant over time (linear) or not (quadratic). A spline model with a transition point at 60 was estimated in order to explore whether decline only begins at 60 (as suggested by data from the Seattle Longitudinal Studies and Whitehall II), or whether there is a difference of the speed of decline before and after this age. The models were estimated using PROC MIXED in SAS 9.3 [22]. Covariance matrices were assumed to be unstructured. Practice effects in search speed were investigated by comparing accuracy of target identification, in addition to the number of letters covered, over each wave. This measure estimated test-retest effects by comparing the accuracy of target identification (correct hits minus misses) but not used as a variable in the main analyses.

Associations with both intercept and slope were sequentially estimated for gender, early life, socio-economic and health factors. Fit was compared by selecting the model with the lowest BIC. Model 1: adjusted for gender. Model 2: additionally adjusted for early life factors (parental education, childhood cognition and educational attainment). Model 3: additionally adjusted for SEP. Model 4: additionally adjusted for health factors (smoking, BMI, systolic blood pressure, diabetes, stroke, rose angina, and cancer). We used cases where complete data were available for all covariates. Sensitivity analyses to quantify differences due to selective attrition through death were undertaken by re-estimating models restricted to only those who remained alive throughout the study period. Stata version 12.1 and SAS 9.3 were used for all statistical procedures (full details in data supplement).

Decline in Search Speed and Verbal Memory Over 26 Years of Midlife

\section{Results}

\section{Characteristics of Participants}

The sample characteristics for the 3,185 men and women included in these analyses are shown in Table 1. Half of the sample was male $(n=1,611,51 \%), 1,059$ (33\%) had educational qualifications at "Advanced" level or beyond, and at age 43 average BMI was $25.5 \mathrm{~kg} / \mathrm{m}^{2}$ and $28 \%$ were current smokers. Cumulative deaths for the period under study (from age 43) were: 199 by age 53,355 by age 60,529 by age 65 , and 715 by the end of the 69th year. Online supplemental Table S1, data supplement (for all online suppl. material, see www.karger.com/ doi/10.1159/000481136) shows the number of individuals undergoing cognitive assessment at each wave. Of 2,147 individuals assessed at age 69, 1,642 (76\%) had measures of search speed at all 4 time points; 1,592 (74\%) had 4 measures of verbal memory. For search speed, correlation of scores at each assessment until age 69 ranged from 0.43 to 0.60 . For verbal memory, correlation across waves was slightly higher ( $p=0.60$ to 0.67$)$. Correlation between verbal memory and search speed at age 43 was low ( $p=$ $0.16)$. Average cognitive scores at each age tested tended 
Table 2. Change in midlife performance in search speed from age 43 in a sample of 2,612 individuals ( 8,162 observations) with complete covariate data

\begin{tabular}{|c|c|c|c|c|c|c|c|c|c|c|c|c|c|c|c|c|}
\hline & \multicolumn{4}{|c|}{ Model 1 sex-adjusted } & \multicolumn{4}{|c|}{ Model $2+$ early life factors } & \multicolumn{4}{|c|}{$\begin{array}{l}\text { Model } 3+\text { aocioeconomic } \\
\text { position }\end{array}$} & \multicolumn{4}{|c|}{ Model $4+$ health factors } \\
\hline & beta & LCI & UCI & $p$ value & beta & LCI & UCI & $p$ value & beta & LCI & UCI & $p$ value & beta & LCI & UCI & $p$ value \\
\hline Intercept & 397.88 & 392.68 & 403.09 & $<0.001$ & 388.96 & 382.47 & 395.46 & $<0.001$ & 385.62 & 377.66 & 393.59 & $<0.001$ & 411.89 & 395.37 & 428.41 & $<0.001$ \\
\hline Gender, male & -23.43 & -29.33 & -17.53 & $<0.001$ & -23.87 & -30.09 & -17.65 & $<0.001$ & -24.66 & -30.95 & -18.37 & $<0.001$ & -22.80 & -29.54 & -16.92 & $<0.001$ \\
\hline Father's education & & & & & 8.48 & 3.44 & 13.51 & 0.001 & 7.91 & 2.82 & 12.99 & 0.002 & 8.35 & 3.18 & 13.53 & 0.001 \\
\hline$<$ Ordinary & & & & & {$[\mathrm{ref}]$} & & & & {$[\mathrm{ref}]$} & & & & [ref] & & & \\
\hline Ordinary & & & & & 2.73 & -3.25 & 8.73 & 0.37 & 1.84 & -4.23 & 7.93 & 55 & 1.53 & -4.64 & 7.70 & 0.62 \\
\hline Advanced & & & & & 15.27 & 8.77 & 21.78 & $<0.001$ & 12.46 & 5.53 & 19.39 & $<0.001$ & 11.92 & 5.14 & 18.69 & $<0.001$ \\
\hline \multicolumn{17}{|l|}{ Occupational class } \\
\hline IV + V & & & & & & & & & {$[\mathrm{ref}]$} & & & & & & & \\
\hline $\mathrm{III} \mathrm{NM}+\mathrm{M}$ & & & & & & & & & 3.53 & -3.36 & 10.43 & 0.31 & & & & \\
\hline Current & & & & & & & & & & & & & -12.13 & -18.24 & -6.02 & $<0.001$ \\
\hline BMI & & & & & & & & & & & & & -1 & -0.70 & -1.26 & -0.14 \\
\hline Diabetes & & & & & & & & & & & & & -25 & -24.50 & -48.12 & -0.89 \\
\hline \multicolumn{17}{|l|}{ Slope } \\
\hline Slope (linear)/ & & & & & & & & & & & & & & & & \\
\hline 5 -years & -49.01 & -51.81 & -46.19 & $<0.001$ & -49.61 & -52.56 & -46.66 & $<0.001$ & -49.51 & -52.48 & -46.55 & $<0.001$ & -49.58 & -52.55 & -46.60 & $<0.001$ \\
\hline Slope (quadratic)/ & & & & & & & & & & & & & & & & \\
\hline 25-years & 4.56 & 4.17 & 4.95 & $<0.001$ & 4.64 & 4.22 & 5.05 & $<0.001$ & 4.62 & 4.21 & 5.04 & $<0.001$ & 4.61 & 4.20 & 5.03 & $<0.001$ \\
\hline Gender & 1.84 & 0.59 & 3.08 & 0.003 & 1.79 & 0.49 & 3.10 & 0.007 & 1.73 & 0.41 & 3.04 & 0.009 & 1.85 & 0.53 & 3.17 & 0.006 \\
\hline
\end{tabular}

Search speed = no. letters scanned; fathers education (primary cf. > primary); childhood cognition (per SD); occupational class at age 43 defined by Registrar General; BMI body mass index at age 43 (per kg/ $\mathrm{m}^{2}$ ); diabetes at age 43 (yes $\mathrm{cf}$. no). No associations with stroke, systolic BP or occupational class at age 43 were evident, therefore not included in Model 4.

to decline, and this decline was less appreciable in those with complete cognitive data at all 4 ages (online suppl. Table S2).

\section{Change in Search Speed from Ages 43 to 69}

BIC indices used in preliminary analyses to compare the fit of linear, quadratic, and spline models, showed the quadratic model provided the best fit. Table 2 presents data in 2,612 individuals with complete covariate data. For the average individual with a baseline level of other covariates, the maximally adjusted model estimated 412 letters (out of 450) scanned at age 43. The overall rate of change, which included a quadratic term, estimated a decline of 49.6 letters/5-years less 4.6 letters, with women declining less through this time (Table 2, model 4). Accuracy of target identification also declined between age 43 and 69 (data supplement, online suppl. Table S2), suggesting that practice effects were not likely to account for the slowing in the decline observed.
Women scanned on average 22.8 more letters at age 43; higher levels of father's education, childhood cognition, and educational attainment by age 26 were also associated with higher scores in search speed at age 43 (Table 2). Women had slower decline compared to men (1.9 letters/5-years; Table 2, model 4). Figure 1 plots the average change in search speed between ages 43 and 69 . Sensitivity analyses including only those individuals who were alive at the last follow-up were performed, with minimal change evident in the estimated parameters, all of which were in the same direction as shown in Table 2 (data supplement, online suppl. Table S3).

\section{Change in Verbal Memory from Age 43 to age 69}

These models were based on 2,591 individuals with complete covariate data. The same 3 trajectories tested in terms of search speed (linear, quadratic, and spline models) showed that the spline model with a transition point at age 60 gave the best fit (Table 3). Such a model divides the data 


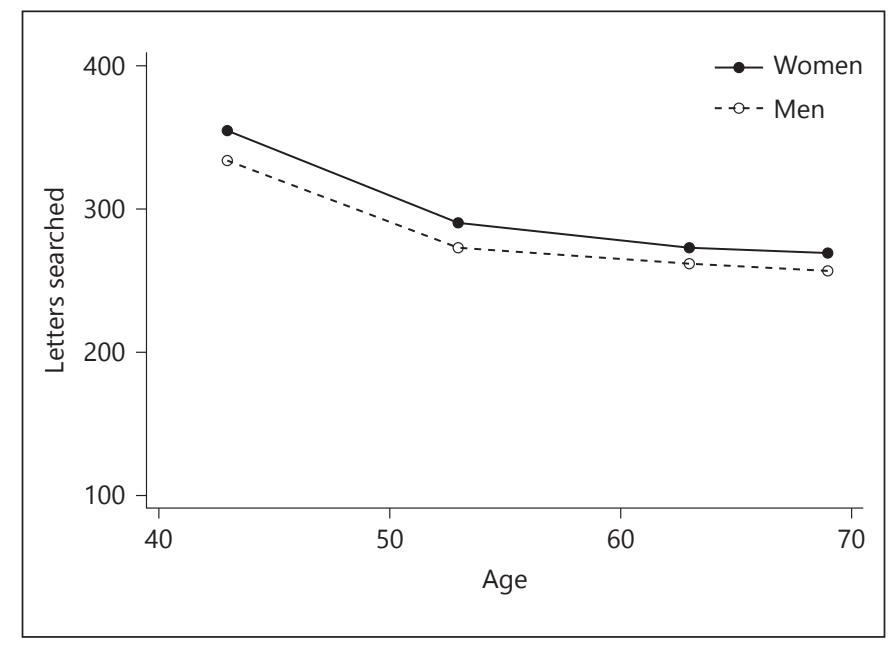

Fig. 1. Change in search speed over midlife. Mean scores for men and women shown at each time point between ages 43 and 69 .

into 2 segments of time and fits a linear trajectory to each of the segments. Thus, spline 1 represents the linear change from age 43 to the transition point - at age 60 - whereas spline 2 represents the linear change from age 60 to age 69. For the fully adjusted model (Table 3, Model 4 ) the average number of words correctly recalled at the transition point was 24.1. Therefore, on average there was an overall decline of 0.2 words/5-years up to age 60 and 0.95 words/5-years thereafter. As with search speed, the intercept was significantly higher for women, and for those with higher levels in father's education, childhood cognition and educational attainment, even after adjusting for other factors in adulthood (Table 3, models 1-4). Lower occupational class, current smoking, higher BMI and having experienced a stroke by age 43 were also associated with memory scores at age 43 . Educational attainment was associated with faster decline after age 60 (additional loss of 0.28 words/5-years in those with highest, compared with the lowest, educational attainment (Fig. 2). No other factors were associated with the slope. As with search speed, a sensitivity analysis including only those individuals who were still alive at age 69 gave similar results (data supplement, online suppl. Table S4).

\section{Discussion}

This analysis showed that a degree of decline in both search speed and verbal memory is evident across midlife, but the temporal sequence of these changes differs. Decline in search speed appeared to decelerate over this time

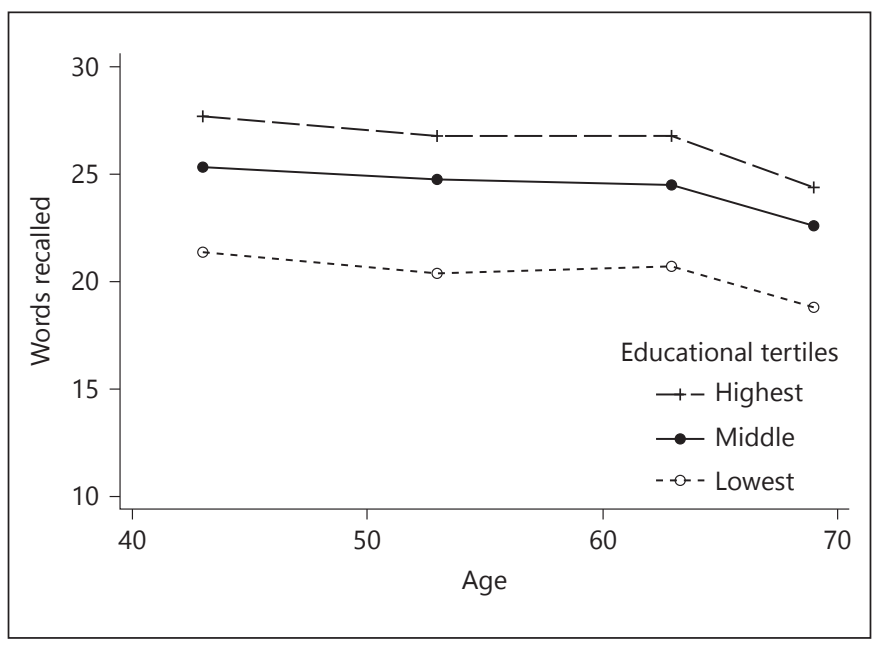

Fig. 2. Change in verbal memory over midlife. Mean scores for by educational attainment by age 26 shown at each time point between ages 43 and 69.

period for both genders. In contrast, decline in verbal memory accelerated after age 60. Paternal education, childhood cognition, educational attainment, adult SEP and health status at 43 were associated with better search speed and verbal memory at age 43. For search speed, women demonstrated higher performance at age 43 , but then declined faster. Those who had attained a higher level of education by age 26 showed a faster decline in verbal memory after age 60 compared with those with lower levels of education, though sustained higher performance overall. Taken together, these findings indicate the importance of factors across the life course in maintaining the cognitive capability developed in childhood.

The major strength of these analyses is the long, prospective follow-up of a nationally representative population sample. This uniquely allows for observed changes across 26 years of midlife to be understood unconfounded by age, and in relation to prospective measures of childhood cognition, education, lifetime SEP and health status. Nonetheless, several limitations must be highlighted. First, in common with other cohort studies, these associations may be underpinned by residual confounding. We adjusted for overall educational attainment by age 26 ; however, there is scope to investigate the effects of education and cognitive development in more detail. By using randomeffects models and complete case analyses for covariates, we assumed data were missing at random, which may not be the case. Finally, some of the observed associations may be subject to secular trends, particularly in education, and therefore specific to this British post-war generation [23]. 
Table 3. Change in midlife performance in verbal memory from age 43 in a sample of 2,591 individuals (8,015 observations) with complete covariate data

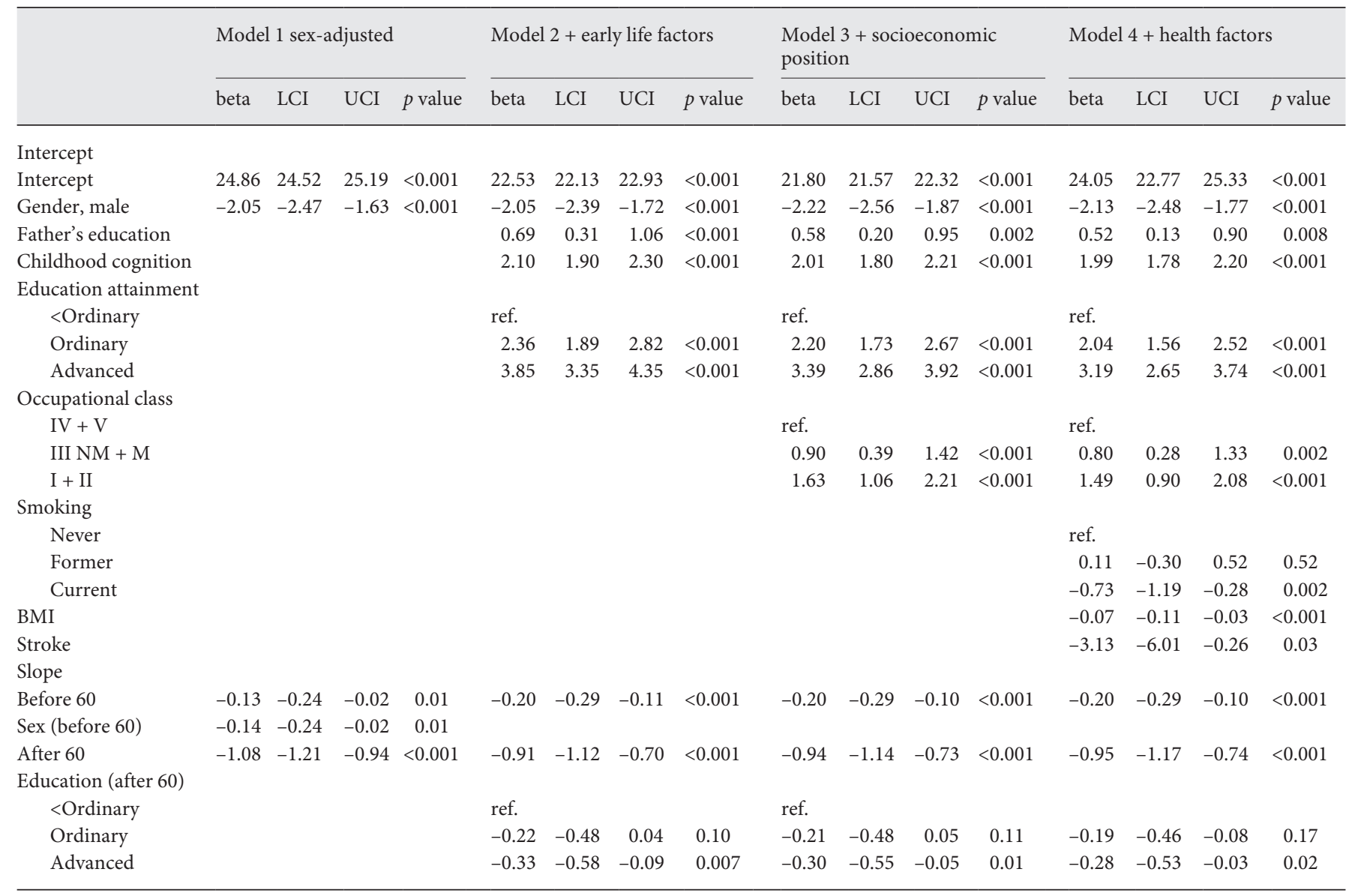

Memory = no. words recalled; fathers education (primary cf. > primary); childhood cognition (per SD); occupational class defined by Registrar General; BMI body mass index at age $43\left(\right.$ per $\mathrm{kg} / \mathrm{m}^{2}$ ); diabetes at age 43 (yes cf. no); systolic BP blood pressure at age 43 (per $\mathrm{mm} \mathrm{Hg}$ ). No associations with diabetes at age 43 were evident, therefore not included in Model 4.

The overall trajectory of change in search speed appears to show that decline slows over the observed time period across midlife. We could not attribute this deceleration to practice effects, nor to differential attrition due to death. In comparing practice effects quantified in other studies [24], it may be that such effects have different magnitudes over the life course, though one notable difference with NSHD is that the intervals are much longer (5-10 years between testing). In addition, the distribution of search speed scores did not suggest that either ceiling or floor effects were at play. No comparable study has reported this slowing of decline prospectively, though cross-sectional normative data from the Woodcock-Johnson Psycho-Educational Battery are consistent with this shape between ages 40 and 70, before greater age-associated changes become evident [25]. In NSHD, it remains to be seen if decline in search speed in NSHD at older ages recapitulates the cross-sectional findings beyond age 70 . The findings in respect of verbal memory and education are consistent with the findings of other studies with smaller samples describing change over this age range $[26,27]$. In NSHD, though faster declines were evident in those with more education after age 60 , the higher initial intercept shows the overall area under the curve to be greater in this group. While there were only 5 time points where a spline knot could be placed, theoretical reasons to do so at age 60 would be consistent with other longitudinal studies [24], with subsequent confirmation that age 60 emerged through a data-driven process. Several studies consistently report that education leads to increase cognitive capability in adulthood, but how this influences subsequent decline is much less well understood $[28,29]$. Mechanisms are difficult to infer, but it should be 
emphasized in this analysis that the absolute change is modest and our findings merit further follow-up and validation in other samples. Overall, while the gains from education demonstrated in an earlier analysis of NSHD [7] appear to persist well after age 60, the general effect of education probably diminishes thereafter.

Both longitudinal measures have a degree of comparability to other tests of search speed and verbal memory. For example, the visual matching task from the Woodcock-Johnson Psycho-Educational Battery and the letter cancellation task are typical of perceptual speed tasks in that the primary manifestation of individual differences measured by the number of items correctly completed in the allotted time [25]. The verbal memory task word list test devised for NSHD is closely related to the California Verbal Learning Test [30] and measures are likely to be correspondingly similar.

With regard to health-related factors, in a sample aged 40-44 followed over 8 years, the PATH Through Life (PATH) Project showed a decline from baseline in memory and processing speed associated with cardiovascular risk factors [31]. Consistent with this, the Framingham Offspring Cohort study reported changes over 7 years in memory and executive function as well as MRI indices of vascular disease and hippocampal atrophy in a sample aged 54 (SD 9) years at baseline [32]. Conversely, the Midlife in the United States study demonstrated changes over 10 years in episodic memory and executive dysfunction appreciable in 4,955 individuals across age range 2475 years that appeared to be independent of health status [33]. Our data is broadly comparable with these findings, with no clear evidence that decline observed over these longer periods of follow-up is appreciably driven by health status at the beginning of this period. Nonetheless, it is prudent that midlife should be a time for identifying modifiable risks for maintaining later cognitive capabilities.

In describing the decline of verbal memory and search speed during midlife, we show that this remains an important period for maintaining lifelong cognitive capability. By implication, pathways to cognitive impairment and dementia in older age may become apparent at this age. Although better cognitive development has been associated with slower decline in later life $[7,34]$ in the present study, factors earlier in life influencing peak cognition had little additional bearing on a subsequent rate of decline. This was also the case for health factors such as diabetes and angina at age 43 , though the proportion of individuals with these conditions at this age was low. Therefore, the degree to which midlife health (e.g., cardiovascular disease) might influence subsequent dementia risk remains unclear. While NSHD has previously reported an association between smoking - itself an indicator of poor health and cognition $[35,36]$, it may be that the cognitive impact of poor health in midlife is not evident even by age 69 . This would be consistent with studies of midlife hypertension where associations with dementia and cognitive impairment over 20 years later have been observed $[37,38]$. Nonetheless, adopting a lifelong approach to cognitive capability, which emphasises a role for early life in maximising peak cognitive reserve [39], and for midlife in maintaining cognitive capability, may promote public health strategies to modify socioeconomic conditions in addition to those focused on improving biological health. At the individual level, cognitive decline could be regarded as a marker of health status in mid-life, which may be reversible if changes to lifestyle are made [40].

\section{Acknowledgements}

The authors thank all study members of NSHD and NSHD scientific and data collection teams. Data used in this publication is available upon request to the MRC NSHD Data Sharing Committee. Further details can be found at: http://www.nshd.mrc.ac.uk/ data. doi: 10.5522/NSHD/Q101; doi: 10.5522/NSHD/Q102; doi: $10.5522 /$ NSHD/Q103. Daniel Davis had full access to all the data in the study and takes responsibility for the integrity of the data and the accuracy of the data analysis.

\section{Funding Sources}

The NSHD and D.K., M.R., and R.H. are supported by core funding and grant funding (programme codes: MC_UU_12019/1, MC_UU_12019/3) from the UK MRC. D.D. is funded through a Wellcome Trust Intermediate Clinical Fellowship (WT107467) and R.B. and G.M.T. are supported by the National Institute on Aging of the National Institutes of Health under award number P01AG043362. No funder had any role in the following aspects: design and conduct of the study; collection, management, analysis, and interpretation of the data; preparation, review, or approval of the manuscript; decision to submit the manuscript for publication. The authors declare no conflicts of interest.

References

Neuroepidemiology 2017;49:121-128

Richards M, Deary IJ: A life course approach to cognitive capability; in Kuh D, Cooper R, Hardy R, Richards M, Ben-Shlomo Y (eds): A Life Course Approach to Healthy Ageing. Oxford, Oxford University Press, 2014.

2 Matthews FE, Stephan BC, Robinson L, Jagger C, Barnes LE, Arthur A, Brayne C; Cognitive Function and Ageing Studies (CFAS) Collaboration: A two decade dementia incidence comparison from the cognitive function and ageing studies I and II. Nat Commun 2016;7:11398. 
3 Willis SL, Martin M, Rocke C: Longitudinal perspectives on midlife development: stability and change. Eur J Ageing 2010;7:131-134.

4 Park DC, Reuter-Lorenz P: The adaptive brain: aging and neurocognitive scaffolding. Annu Rev Psychol 2009;60:173-196.

5 Salthouse T: Developmental Influences on Adult Intelligence: The Seattle Longitudinal Study, K. Warner Schaie. Oxford, Oxford University Press, 2005. Intelligence 2005;33: 551-554.

6 Singh-Manoux A, Kivimaki M, Glymour MM, Elbaz A, Berr C, Ebmeier KP, Ferrie JE, Dugravot A: Timing of onset of cognitive decline: results from Whitehall II prospective cohort study. BMJ 2012;344:d7622.

7 Richards M, Shipley B, Fuhrer R, Wadsworth ME: Cognitive ability in childhood and cognitive decline in mid-life: longitudinal birth cohort study. BMJ 2004;328:552.

8 Plassman BL, Williams JW Jr, Burke JR, Holsinger T, Benjamin S: Systematic review: factors associated with risk for and possible prevention of cognitive decline in later life. Ann Intern Med 2010;153:182-193.

9 Deckers K, van Boxtel MP, Schiepers OJ, de Vugt M, Munoz Sanchez JL, Anstey KJ, Brayne C, Dartigues JF, Engedal K, Kivipelto M, Ritchie K, Starr JM, Yaffe K, Irving K, Verhey FR, Kohler S: Target risk factors for dementia prevention: a systematic review and Delphi consensus study on the evidence from observational studies. Int J Geriatr Psychiatry 2015;30:234-246.

10 Rabbitt P: Does it all go together when it goes? The nineteenth bartlett memorial lecture. Q J Exp Psychol A 1993;46:385-434.

11 Wadsworth M, Kuh D, Richards M, Hardy R: Cohort Profile: the 1946 national birth cohort (MRC national survey of health and development). Int J Epidemiol 2006;35:49-54.

12 Kuh D, Pierce M, Adams J, Deanfield J, Ekelund U, Friberg P, Ghosh AK, Harwood N, Hughes A, Macfarlane PW, Mishra G, Pellerin D, Wong A, Stephen AM, Richards M, Hardy R: Cohort profile: updating the cohort profile for the MRC national survey of health and development: a new clinic-based data collection for ageing research. Int J Epidemiol 2011; 40:e1-e9.

13 Wadsworth ME, Mann SL, Rodgers B, Kuh DJ, Hilder WS, Yusuf EJ: Loss and representativeness in a 43 year follow up of a national birth cohort. J Epidemiol Community Health 1992;46:300-304.

14 Stafford M, Black S, Shah I, Hardy R, Pierce M, Richards M, Wong A, Kuh D: Using a birth cohort to study ageing: representativeness and response rates in the national survey of health and development. Eur J Ageing 2013; 10:145-157.

15 Kuh D, Wong A, Shah I, Moore A, Popham M, Curran P, Davis D, Sharma N, Richards M, Stafford M, Hardy R, Cooper R: The MRC na- tional survey of health and development reaches age 70: maintaining participation at older ages in a birth cohort study. Eur J Epidemiol 2016;31:1135-1147.

16 Davis D, Cooper R, Terrera GM, Hardy R, Richards M, Kuh D: Verbal memory and search speed in early midlife are associated with mortality over 25 years' follow-up, independently of health status and early life factors: a British birth cohort study. Int J Epidemiol 2016;45:1216-1225

17 Richards M, Sacker A: Lifetime antecedents of cognitive reserve. J Clin Exp Neuropsychol 2003;25:614-624.

18 Douglas JWB: The Home and the School: A Study of Ability and Attainment in the Primary Schools. London, MacGibbon and Kee, 1964.

19 Rose GA: The diagnosis of ischaemic heart pain and intermittent claudication in field surveys. Bull World Health Organ 1962;27: 645-658.

20 Kenward MG, Roger JH: Small sample inference for fixed effects from restricted maximum likelihood. Biometrics 1997;53:983-997.

21 Arnau J, Bendayan R, Blanca MJ, Bono R: The effect of skewness and kurtosis on the Kenward-Roger approximation when group distributions differ. Psicothema 2014;26:279285.

22 Ibrahim JG, Molenberghs G: Missing data methods in longitudinal studies: a review. Test (Madr) 2009;18:1-43.

23 Richards M, Power C, Sacker A: Paths to literacy and numeracy problems: evidence from two British birth cohorts. J Epidemiol Community Health 2009;63:239-244.

24 Salthouse TA: Influence of age on practice effects in longitudinal neurocognitive change. Neuropsychology 2010;24:563-572.

25 Salthouse TA: Aging and measures of processing speed. Biol Psychol 2000;54:35-54.

26 Szoeke C, Lehert P, Henderson VW, Dennerstein L, Desmond P, Campbell S: Predictive factors for verbal memory performance over decades of aging: data from the women's healthy ageing project. Am J Geriatr Psychiatry 2016;24:857-867.

27 Lundervold AJ, Wollschlager D, Wehling E: Age and sex related changes in episodic memory function in middle aged and older adults. Scand J Psychol 2014;55:225-232.

28 Cadar D, Robitaille A, Clouston S, Hofer SM, Piccinin AM, Muniz-Terrera G: An international evaluation of cognitive reserve and memory changes in early old age in 10 European countries. Neuroepidemiology 2017;48:9-20.

29 Piccinin AM, Muniz-Terrera G, Clouston S, Reynolds CA, Thorvaldsson V, Deary IJ, Deeg DJ, Johansson B, Mackinnon A, Spiro A 3rd, Starr JM, Skoog I, Hofer SM: Coordinated analysis of age, sex, and education effects on change in MMSE scores. J Gerontol B Psychol Sci Soc Sci 2013;68:374-390.
30 Elwood RW: The California verbal learning test: psychometric characteristics and clinical application. Neuropsychol Rev 1995;5:173201

31 Anstey KJ, Sargent-Cox K, Garde E, Cherbuin $\mathrm{N}$, Butterworth P: Cognitive development over 8 years in midlife and its association with cardiovascular risk factors. Neuropsychology 2014;28:653-665.

32 Debette S, Seshadri S, Beiser A, Au R, Himali JJ, Palumbo C, Wolf PA, DeCarli C: Midlife vascular risk factor exposure accelerates structural brain aging and cognitive decline. Neurology 2011;77:461-468.

33 Agrigoroaei S, Lachman ME: Cognitive functioning in midlife and old age: combined effects of psychosocial and behavioral factors. J Gerontol B Psychol Sci Soc Sci 2011;66 (suppl 1):i130-i140.

34 Gow AJ, Johnson W, Pattie A, Brett CE, Roberts B, Starr JM, Deary IJ: Stability and change in intelligence from age 11 to ages 70 , 79, and 87: the Lothian Birth Cohorts of 1921 and 1936. Psychol Aging 2011;26:232240.

35 Richards M, Jarvis MJ, Thompson N, Wadsworth ME: Cigarette smoking and cognitive decline in midlife: evidence from a prospective birth cohort study. Am J Public Health 2003;93:994-998.

36 Kuh D, Shah I, Richards M, Mishra G, Wadsworth M, Hardy R: Do childhood cognitive ability or smoking behaviour explain the influence of lifetime socio-economic conditions on premature adult mortality in a British post war birth cohort? Soc Sci Med 2009;68:15651573.

37 Launer LJ, Hughes T, Yu B, Masaki K, Petrovitch $H$, Ross GW, White LR: Lowering midlife levels of systolic blood pressure as a public health strategy to reduce late-life dementia: perspective from the honolulu heart program/honolulu Asia aging study. Hypertension 2010;55:1352-1359.

38 Elias MF, Goodell AL, Dore GA: Hypertension and cognitive functioning: a perspective in historical context. Hypertension 2012;60: 260-268.

39 Richards M, Deary IJ: A life course approach to cognitive reserve: a model for cognitive aging and development? Ann Neurol 2005;58: 617-622.

40 Ngandu T, Lehtisalo J, Solomon A, Levalahti E, Ahtiluoto S, Antikainen R, Backman L, Hanninen T, Jula A, Laatikainen T, Lindstrom J, Mangialasche F, Paajanen T, Pajala S, Peltonen M, Rauramaa R, Stigsdotter-Neely A, Strandberg T, Tuomilehto J, Soininen $\mathrm{H}$, Kivipelto M: A 2 year multidomain intervention of diet, exercise, cognitive training, and vascular risk monitoring versus control to prevent cognitive decline in at-risk elderly people (FINGER): a randomised controlled trial. Lancet 2015;385:2255-2263. 